
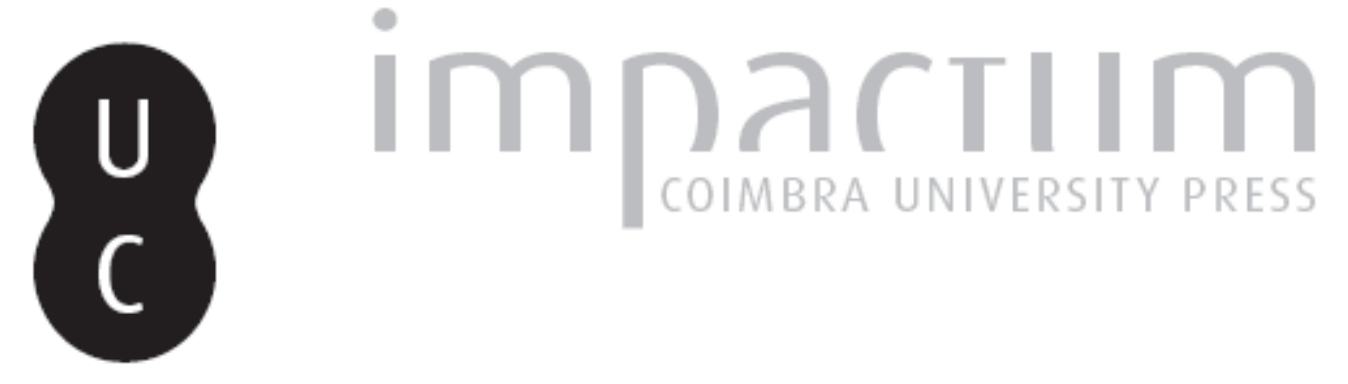

\title{
A perícia médico-legal em casos de violência nas relações de intimidade: contributo para a qualidade
}

Autor(es): $\quad$ Mouraz, M. José; Magalhães, Teresa

Publicado por: Imprensa da Universidade de Coimbra

URL persistente:

URI:http://hdl.handle.net/10316.2/33162

DOI:

DOI:http://dx.doi.org/10.14195/1647-8630_21_1

Accessed : $\quad$ 26-Apr-2023 10:55:00

A navegação consulta e descarregamento dos títulos inseridos nas Bibliotecas Digitais UC Digitalis, UC Pombalina e UC Impactum, pressupõem a aceitação plena e sem reservas dos Termos e Condições de Uso destas Bibliotecas Digitais, disponíveis em https://digitalis.uc.pt/pt-pt/termos.

Conforme exposto nos referidos Termos e Condições de Uso, o descarregamento de títulos de acesso restrito requer uma licença válida de autorização devendo o utilizador aceder ao(s) documento(s) a partir de um endereço de IP da instituição detentora da supramencionada licença.

Ao utilizador é apenas permitido o descarregamento para uso pessoal, pelo que o emprego do(s) título(s) descarregado(s) para outro fim, designadamente comercial, carece de autorização do respetivo autor ou editor da obra.

Na medida em que todas as obras da UC Digitalis se encontram protegidas pelo Código do Direito de Autor e Direitos Conexos e demais legislação aplicável, toda a cópia, parcial ou total, deste documento, nos casos em que é legalmente admitida, deverá conter ou fazer-se acompanhar por este aviso.

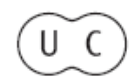




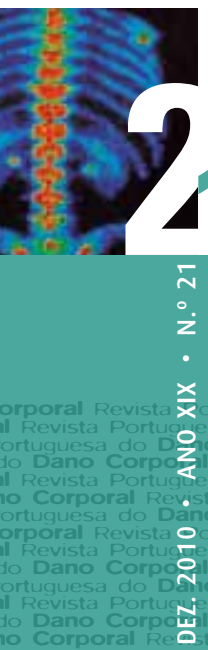

REVISTA PORTUGUESA

do

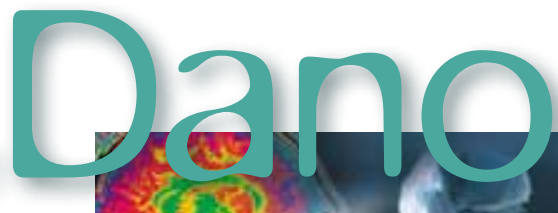

$\dot{z}$

$\dot{x}$

$\frac{x}{x}$

o. corporal Corporal Revista Portuguesa do Dano Corporal

Z

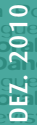

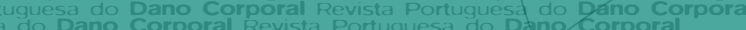

Revista Portuguesa do Dano Corporal Revista Rortuguesa do Dano Corporal

Sa do Dano Corporal Revista Portuguesa do Dano Corporal Revista Portuguesł do Dano Corporal

Portuguesa do Dano Corporal Revista portuguesta do Dano Corporal 


\title{
A perícia médico-legal em casos de violência nas relações de intimidade. Contributo para a qualidade ${ }^{1}$
}

\author{
M. José Mouraz², Teresa Magalhães ${ }^{3}$
}

\section{Introdução}

A violência nas relações de intimidade (VRI) é a que ocorre entre duas pessoas que têm ou tiveram uma relação íntima (Gelles, 1997). A lei portuguesa enquadra-a na violência doméstica considerando-a um crime autónomo e público (Art. $152^{\circ}$ do $\mathrm{CP}$ ). É transversal a todos os estratos sociais, implica múltiplas formas de violência, é muitas vezes subvalorizada pela sociedade e pelas próprias vítimas, implica a intervenção multiprofissional cujos elementos não estão, na maioria das vezes por falta de preparação específica, preparados para trabalhar com estes casos, atrasando a sua detecção, não fazendo diagnósticos correctos e, sobretudo, não sabendo "o que fazer a seguir" para proteger a vítima do mais que provável agravamento da violência ou de a afastar do perigo (Villora et al, 2009; Machado, Gonçalves \& Matos, 2005). As mulheres continuam a ser as principais vítimas.

A avaliação das vítimas é um dos momentos fulcrais no tratamento da VRI, já que permite o diagnóstico da situação, a contextualização da violência, a apreciação do dano global da vítima directa e das eventuais vítimas indirectas, o cálculo de hipotéticos factores de risco de manutenção de violência e, por último, a produção de um importante instrumento de prova que possa ajudar a servir a Justiça (Magalhães, 2010).

1 O presente artigo retoma uma parte do trabalho empírico da tese de Mestrado apresentada à Universidade do Porto pela $1^{\mathrm{a}}$ autora sob orientação da $2^{\mathrm{a}}$, intitulada "A Perícia Médico-Legal nos Casos de Violência nas Relações de Intimidade - contributo para a qualidade".

2 Gabinete Médico-Legal de Viseu - Instituto Nacional de Medicina Legal, I.P.

3 Delegação do Norte do Instituto Nacional de Medicina Legal, I.P.

Faculdade de Medicina da Universidade do Porto

Instituto Ciências Biomédicas Abel Salazar da Universidade do Porto

CENCIFOR - Centro de Ciências Forenses, Portugal 
O Instituto Nacional de Medicina Legal, I.P. (INML) tem vindo a instituir medidas a nível da Clínica Forense, visando harmonizar a actividade pericial, eliminando assimetrias regionais, de forma que vítimas ou agressores possam ser avaliados de maneira uniforme, permitindo a aproximação aos princípios da igualdade e da justiça consagrados na Constituição Portuguesa (Vieira, 2003).

O presente trabalho tem como objectivo, por um lado, analisar se a actual forma de avaliação pericial a vítimas de casos de VRI satisfaz os requisitos necessários a uma correcta avaliação daquelas vítimas, permitindo a obtenção de um relatório que se possa constituir como um instrumento válido na produção da prova em Direito Penal, mas que, simultaneamente, seja capaz de fornecer informação que permita a tomada de medidas de protecção à vítima e, por outro lado, verificar se existem assimetrias entre as zonas onde as vítimas são geralmente observadas: as Delegações e os Gabinetes MédicoLegais do INML, já que existem diferenças de formação entre os respectivos peritos e, por vezes, diferenças de procedimentos de atendimento.

\section{Definição do problema}

A violência nas relações de intimidade constitui um tipo muito particular de violência, de limites por vezes difíceis de definir, que podem ir desde o simples "erguer da voz" em discussões do casal, até ao homicídio qualificado. Por outro lado é, ao contrário dos restantes casos de violência que surgem para exame médico-legal no domínio do Direito Penal, de natureza reiterada (Dutton \& Kropp, 2000), de gravidade crescente e atinge, na maior parte das vezes, outras vítimas igualmente indefesas, como as crianças e idosos. Pelo facto de ser repetida no tempo, às vezes ao longo de dezenas de anos, transforma as vítimas em seres totalmente indefesos, vulneráveis, incapazes de raciocínios lógicos que não sejam os de defesa da sua própria integridade física ou da dos filhos, ou, outras vezes, as leva a situações de tão grave desespero que deixam de ter capacidade de vislumbrar saídas e só lhes ocorre pôr termo à vida (Campbell et al, 2003).

É convicção recente mas generalizada entre os peritos internacionais que a vitimação no lar, além das consequências físicas, tem também consequências psicológicas profundas a curto e a longo prazo (Lisboa, Carmo, Vicente \& Nóvoa, 2003). E efectivamente, também para a medicina Legal, o "dano" deixou de ser apenas o prejuízo material, aquele que deixa "marcas no corpo". É necessário levar em conta o "dano invisível”, aquele que sensorialmente não é perceptível (Corsi, 2003). Por outro lado, tem também de ser avaliado o dano que supõe a aprendizagem da violência, reconhecendo que a socialização em ambientes de violência doméstica aparece como um factor muito importante 
de probabilidade de se ser um agressor ou uma vítima de abuso no futuro (Alberdi \& Matas, 2002).

O Estado Português reconheceu a gravidade deste tipo de crimes e a lei veio recentemente reforçar a necessidade de se olhar para este tipo de violência com olhar diferente, nomeadamente no que concerne a protecção da vítima e a prevenção de futura violência (Assembleia da República, 2007 e 2009). Todavia, a referência principal nos exames em Clínica Forense em Direito Penal, em Portugal, continua a ser o Art. $143^{\circ}$ e o Art. $144^{\circ}$ do Código Penal, "Ofensas à integridade física" simples e graves.

Assim sendo, no caso particular do tratamento da VRI, há questões que se impõe colocar: serão suficientes os elementos recolhidos no exame de Clínica Forense, de forma a possibilitar a realização de um verdadeiro relatório pericial? Será que um exame pericial em âmbito Penal em situações de VRI, deve ser realizado exactamente da mesma forma e dando relevância às mesmas questões como em qualquer outro exame?

Outra questão que se levanta é a de saber se, em Portugal, a forma de produção destas perícias garante igual qualidade, face à constituição diversa e formação assimétrica dos peritos encarregues de assegurar esta actividade médico-legal.

São, então, perguntas de investigação:

a) Até que ponto a informação constante na rubrica "História do Evento" é suficiente para caracterizar a situação de VRI em causa?

b) A rubrica "Antecedentes Pessoais" tem descrito os dados necessários à sua caracterização e tem sido suficientemente abrangente de modo a incluir os hábitos de consumo?

c) O campo "Contexto Familiar" está a ser preenchido de forma a avaliar exaustivamente, os elementos que permitem apreciar a existência de factores de risco (de acordo com o estabelecido pela literatura)?

d) Até que ponto são valorizadas as "Queixas” do foro psicológico e situacional?

e) Contém a rubrica "Discussão" os itens necessários e suficientes para apreciar as situações de VRI?

f) Qual é a pertinência da fotodocumentação e de que forma é ela utilizada pelos peritos?

g) Existem diferenças significativas na realização dos exames que possam ser imputadas a diferentes enquadramentos institucionais dos peritos?

h) Poderá ou deverá a estrutura do relatório pericial ser alterada de forma a melhorar a sua qualidade? 


\section{Material e métodos}

De um ponto de vista operacional, a investigação objectiva-se na análise dos relatórios produzidos pelos peritos, sobre os quais se fez análise de conteúdo. Este é um estudo descritivo desse objecto. Para a avaliação dos pontos fortes e fracos dos relatórios periciais relativos a situações de VRI, foram analisados relatórios elaborados no âmbito da Clínica Forense.

Como critérios de inclusão para esta amostra foram considerados os seguintes:

a) Relatório de Clínica Forense;

b) Elaborado no âmbito do Direito Penal;

c) No Gabinete Médico-Legal de Viseu ou na Delegação do Norte do INML;

d) Por denúncia de VRI contra cônjuge, ex-cônjuge, companheiro(a), ex-companheiro(a), namorado(a), ex-namorado(a);

e) Suposta vítima maior de 17 anos, independentemente do sexo.

Foi feita uma selecção pensada, considerando os primeiros 114 relatórios do Gabinete Médico-Legal de Viseu e os primeiros 110 relatórios da Delegação do Norte do INML, relativos ao ano de 2008. A amostra final totalizou 224, em virtude de termos validado todos os relatórios avaliados, mesmo aqueles que a metodologia recomenda acrescentar para efeitos de substituição de casos inválidos (Tuckman, 2000).

Elaborou-se uma ficha de avaliação da qualidade dos relatórios periciais em Clínica Forense destinada às situações de VRI, através da adaptação da actual ficha de auditoria dos relatórios periciais em uso no INML, incluindo os diversos capítulos do mesmo relatório, mas dando especial presença à explicitação dos itens em que se operacionaliza "a história do evento"; "antecedentes pessoais"; "contexto familiar" e "descrição das queixas" (anexo). A pontuação atribuída variou de -1 a 3 consoante a descrição era "mal estruturada e/ou incompleto/ não incluía dados relevantes" (-1) e uma descrição "correcta" (3). Além disso, a presença ou ausência dos itens referidos que explicitavam a qualidade da descrição foi pontuada de 1 ou 0 , para efeitos de contabilização dos resultados.

Para a adaptação desta ficha foram ainda considerados os instrumentos de avaliação de vítimas de violência conjugal, que se encontram validados e publicados: Danger Assessment (Campbell, 1995, 2004), SPECS/RARA (Metropolitan Police Service, 2003), Domestic Violence Screening Instrument (Williams \& Houghton, 2004), Spousal Assault Risk Assessment (Kropp et al.), 
Questionário de Avaliação de Risco a Vitimas de Violência Doméstica (GNR) e Inventário sobre Violência Conjugal (Machado et al, 2000).

O tratamento estatístico dos dados recolhidos, após codificação e informatização, foi efectuado com o programa SPSS (versão 15.0). Os dados foram analisados de um ponto de vista da estatística descritiva, tendo sido usadas medidas de tendência central, e feitos testes de Qui quadrado $(\chi 2)$ e testes $t$ de student, para averiguar diferenças significativas.

\section{Resultados}

Foram analisados 224 relatórios médicos de Clínica Forense relativos a casos de VRI, 110 (49.1\%) elaborados na Delegação do Norte do INML e 114 (50.9\%) no Gabinete Médico-Legal de Viseu (GML).

O número referente a indivíduos de sexo masculino foi pouco significativo $(n=19,8.5 \%)$, pelo que não considerámos esta variável no estudo subsequente.

\section{História do evento}

Ao analisarmos os modos de presença da "História do evento" nos relatórios, constatamos que 95\% dos relatórios apresenta uma descrição que indica data e hora, tipo de ocorrência, suposto agressor e suposto instrumento de agressão, mas não fazem, por sistema, referência à descrição da ocorrência. Apenas 9 relatórios (4\%), equitativamente divididos entre Delegação e GML, fazem uma descrição onde constam todos os itens. Não existem diferenças no modo de descrever a história do evento entre a Delegação e o Gabinete $(\chi 2=2.270)$. Uma subsequente análise comparativa dos resultados obtidos nos itens relativos e descritivos da história do evento (data, hora, tipo de ocorrência, instrumento de agressão, agressor, descrição da ocorrência, resultado declarado, assistência médica), permite aquilatar as razões pelas quais uma maioria dos relatórios foi considerada como contendo imprecisões: à excepção da descrição da ocorrência, todos os itens constavam dos relatórios com presenças numéricas idênticas. Aquele item, em particular, estava referido em apenas 7\% dos relatórios da Delegação e 4\% dos relatórios do GML (tabela 1). 
Tabela 1. Análise comparativa dos resultados nos itens relativos e descritivos da História do Evento divididos por local de origem

\begin{tabular}{|c|c|c|c|c|c|c|c|c|c|}
\hline \multirow{2}{*}{ Referência } & \multicolumn{3}{|c|}{ Delegação } & \multicolumn{3}{|c|}{ Gabinete } & \multicolumn{3}{|c|}{ Total } \\
\hline & Média & $\mathrm{n}$ & SD & Média & $\mathrm{n}$ & $\mathrm{SD}$ & Média & $\mathrm{n}$ & SD \\
\hline Data & 1.00 & 110 & 0.00 & 0.99 & 114 & 0.09 & 1.00 & 224 & 0.07 \\
\hline Hora & 1.00 & 110 & 0.00 & 0.99 & 114 & 0.09 & 1.00 & 224 & 0.07 \\
\hline Tipo de ocorrência & 1.00 & 110 & 0.00 & 0.99 & 114 & 0.09 & 1.00 & 224 & 0.07 \\
\hline $\begin{array}{l}\text { Instrumento de } \\
\text { agressão }\end{array}$ & 1.00 & 110 & 0.00 & 0.99 & 114 & 0.09 & 1.00 & 224 & 0.07 \\
\hline Agressor & 1.00 & 110 & 0.00 & 0.99 & 114 & 0.09 & 1.00 & 224 & 0.07 \\
\hline $\begin{array}{l}\text { Descrição da } \\
\text { ocorrência }\end{array}$ & 0.07 & 110 & 0.26 & 0.04 & 114 & 0.18 & 0.05 & 224 & 0.23 \\
\hline Resultado declarado & 0.87 & 110 & 0.33 & 0.90 & 114 & 0.30 & 0.89 & 224 & 0.32 \\
\hline Assistência médica & 0.98 & 110 & 0.13 & 0.99 & 114 & 0.09 & 0.99 & 224 & 0.12 \\
\hline
\end{tabular}

\section{Dados documentais}

A maior parte dos relatórios (82.1\%) apresentaram uma descrição aceitável desta rubrica, se levarmos em consideração que num número significativo de casos não existe ou não é apresentada qualquer documentação.

Em 16.7\% dos relatórios do GML, não se encontrou qualquer referência a esta rubrica, a qual tinha sido apagada do relatório. $\mathrm{O}$ valor do $\chi 2=23.362$ indicia que existe uma diferença entre os dois grupos de relatórios considerados, para um $\mathrm{p}=0.001$.

Apenas $10 \%$ se referiu à entidade, $8 \%$ à data da documentação e $9 \%$ ao extracto da documentação.

\section{Antecedentes pessoais}

Dos 224 relatórios, apenas dois $(0.8 \%)$ incluíam referência aos três tipos de antecedentes pessoais considerados (patológicos, traumáticos e de hábitos de consumo). A grande maioria (81.3\%), fazia referência a antecedentes patológicos ou traumáticos, mas muito raramente foi feita referência a hábitos de consumo. $\mathrm{O}$ valor do $\chi 2$ é de 31.846 para um $\mathrm{p}=0.001$, pelo que é significativa a diferença entre os dois grupos considerados.

Os antecedentes patológicos e traumáticos são referidos em quase todos os relatórios da Delegação, 97\% e 95\%, respectivamente, enquanto os relatórios do GML os referem apenas em $66 \%$ e $54 \%$ (tabela 2). 
Tabela 2. Análise comparativa dos resultados obtidos nos itens relativos e descritivos dos Antecedentes Pessoais distribuídos pela sua origem ${ }^{4}$

\begin{tabular}{|c|c|c|c|c|c|c|c|c|c|}
\hline \multirow{2}{*}{ Referência } & \multicolumn{3}{|c|}{ Delegação } & \multicolumn{3}{|c|}{ Gabinete } & \multicolumn{3}{|c|}{ Total } \\
\hline & Média & $\mathrm{n}$ & SD & Média & $\mathrm{n}$ & SD & Média & $\mathrm{n}$ & $\mathrm{SD}$ \\
\hline $\begin{array}{l}\text { Antecedentes pessoais } \\
\text { relevantes (patológicos) }\end{array}$ & 0.97 & 110 & 0.16 & 0.66 & 114 & 0.48 & 0.81 & 224 & 0.39 \\
\hline $\begin{array}{l}\text { Antecedentes pessoais } \\
\text { relevantes (traumáticos) }\end{array}$ & 0.95 & 110 & 0.23 & 0.54 & 114 & 0.50 & 0.74 & 224 & 0.44 \\
\hline $\begin{array}{l}\text { Antecedentes pessoais } \\
\text { relevantes (hábitos de } \\
\text { consumo) }\end{array}$ & 0.01 & 110 & 0.10 & 0.01 & 114 & 0.09 & 0.01 & 224 & 0.09 \\
\hline
\end{tabular}

\section{Contexto familiar}

Nesta rubrica foi considerada a presença ou ausência de 18 itens (cf. anexo) que, desdobram a componente contexto familiar. Dos 224 relatórios apenas um tinha assinalado todos os itens. Em 71 (31.79\%) foram considerados pelo menos nove itens, enquanto em 152 (67.9\%), foi referido um número inferior. A grande maioria das vezes, nos relatórios da Delegação, faz-se a referência ao envio ao Serviço Social, enquanto no GML, se refere apenas que existe historial de maus-tratos, o que se traduz numa diferença significativa $(\chi 2=76,929 ; \mathrm{p}<0.001)$.

Por outro lado, verificamos que cerca de um quarto dos relatórios $(25 \%$ da Delegação e 33\% do GML) se referem à constituição do agregado familiar. Já a escolaridade, as profissões e os antecedentes patológicos das pessoas que formam o agregado familiar, constam em percentagem inferior a $10 \%$. Também em 10\% dos relatórios existe referência à existência de comportamentos desviantes daqueles elementos (tabela 3).

Tabela 3. Análise comparativa dos resultados obtidos nos itens relativos ao Contexto Familiar por origem $\left(1^{\circ}\right.$ conjunto de itens)

\begin{tabular}{|c|c|c|c|c|c|c|c|c|c|}
\hline \multirow{2}{*}{$\begin{array}{l}\text { Referência } \\
\text { Agregado familiar }\end{array}$} & \multicolumn{3}{|c|}{ Delegação } & \multicolumn{3}{|c|}{ Gabinete } & \multicolumn{3}{|c|}{ Total } \\
\hline & Média & $\mathrm{n}$ & SD & Média & $\mathrm{n}$ & SD & Média & $\mathrm{n}$ & SD \\
\hline (pessoas) & 0.25 & 110 & 0.44 & 0.33 & 114 & 0.47 & 0.29 & 224 & 0.46 \\
\hline (escolaridade) & 0.05 & 110 & 0.23 & 0.01 & 114 & 0.09 & 0.03 & 224 & 0.17 \\
\hline (profissões) & 0.08 & 110 & 0.28 & 0.04 & 114 & 0.18 & 0.06 & 224 & 0.23 \\
\hline $\begin{array}{l}\text { (antecedentes } \\
\text { patológicos) }\end{array}$ & 0.07 & 110 & 0.26 & 0.11 & 114 & 0.32 & 0.09 & 224 & 0.29 \\
\hline $\begin{array}{l}\text { (comportamentos } \\
\text { desviantes) }\end{array}$ & 0.10 & 110 & 0.30 & 0.11 & 114 & 0.31 & 0.10 & 224 & 0.30 \\
\hline
\end{tabular}

4 Considerando que a variação de resposta se situava entre 0 e 1 , os valores assinalados podem ser lidos como se de percentagens se tratasse. 
Um quarto de todos os relatórios refere-se à data do início da relação de intimidade e um pouco mais de um quarto à data de início do abuso, sendo os valores do GML, ligeiramente superiores aos da Delegação.

A referência ao tipo de abuso inicial, foi registada em 17\% dos casos, já a forma de evolução dos abusos quanto ao tipo, à frequência, ao grau de ameaças ou seu tipo, foi inferior a $10 \%$ e apenas em $2 \%$ se encontrou referência a agressões durante a gravidez ou a ameaças com armas de fogo (tabela 4).

Tabela 4. Análise comparativa dos resultados obtidos nos itens relativos ao Contexto Familiar por origem ( $2^{\circ}$ conjunto de itens)

\begin{tabular}{|c|c|c|c|c|c|c|c|c|c|}
\hline \multirow{2}{*}{ Referência } & \multicolumn{3}{|c|}{ Delegação } & \multicolumn{3}{|c|}{ Gabinete } & \multicolumn{3}{|c|}{ Total } \\
\hline & Média & $\mathrm{n}$ & SD & Média & $\mathrm{n}$ & SD & Média & $\mathrm{n}$ & SD \\
\hline $\begin{array}{l}\text { Data do início da } \\
\text { relação de intimidade } \\
\text { actual }\end{array}$ & 0.20 & 110 & 0.40 & 0.30 & 114 & 0.46 & 0.25 & 224 & 0.43 \\
\hline $\begin{array}{l}\text { Data do início do } \\
\text { abuso }\end{array}$ & 0.24 & 110 & 0.43 & 0.31 & 114 & 0.46 & 0.27 & 224 & 0.45 \\
\hline $\begin{array}{l}\text { Tipo do abuso } \\
\text { inicial (físico, sexual, } \\
\text { psicológico/emocional, } \\
\text { exploração económica) }\end{array}$ & 0.22 & 110 & 0.41 & 0.11 & 114 & 0.32 & 0.17 & 224 & 0.37 \\
\hline $\begin{array}{l}\text { Evolução dos abusos } \\
\text { quanto ao seu tipo }\end{array}$ & 0.08 & 110 & 0.28 & 0.06 & 114 & 0.24 & 0.07 & 224 & 0.26 \\
\hline $\begin{array}{l}\text { Evolução dos abusos } \\
\text { quanto à sua frequência }\end{array}$ & 0.04 & 110 & 0.19 & 0.04 & 114 & 0.18 & 0.04 & 224 & 0.19 \\
\hline $\begin{array}{l}\text { Evolução dos abusos } \\
\text { quanto ao seu tipo e } \\
\text { grau de ameaças }\end{array}$ & 0.09 & 110 & 0.29 & 0.03 & 114 & 0.16 & 0.06 & 224.0 & 0.23 \\
\hline $\begin{array}{l}\text { Existência de agressões } \\
\text { durante a gravidez }\end{array}$ & 0.03 & 110 & 0.16 & 0.01 & 114 & 0.09 & 0.02 & 224.0 & 0.13 \\
\hline Ameaças com armas & 0.05 & 110 & 0.21 & 0.00 & 114 & 0.00 & 0.02 & 224.0 & 0.15 \\
\hline
\end{tabular}

A referência a ameaças de homicídio por parte do suposto abusador foi feita em 11\% dos relatórios da Delegação e em 4\% dos relatórios do GML; referências a queixas anteriores às autoridades foram registadas em 25\% da Delegação e $12 \%$ do GML, enquanto referências a queixas retiradas apenas se encontraram em 9\% dos relatórios da Delegação e em 2\% do GML; notas sobre detenções anteriores do suposto abusador encontraram-se em $2 \%$ do total dos relatórios; apenas em $0.3 \%$ se referiu a existência de eventual situação de violência nas famílias de origem da vítima e agressor; referência a outras pessoas expostas a cenas de violência ou a serem vítimas de abuso fez-se apenas em 14\% dos casos; referências à convicção da suposta vítima 
de poder ser alvo de tentativa de homicídio, à existência de algum tipo de ideação suicida e à existência de apoio social/familiar com que a suposta vítima possa contar, constavam em menos de 5\% dos relatórios (tabela 5).

Tabela 5. Análise comparativa dos resultados obtidos nos itens relativos ao Contexto Familiar por origem ( $3^{\circ}$ conjunto de itens)

\begin{tabular}{|c|c|c|c|c|c|c|c|c|c|}
\hline \multirow{2}{*}{ Referência } & \multicolumn{3}{|c|}{ Delegação } & \multicolumn{3}{|c|}{ Gabinete } & \multicolumn{3}{|c|}{ Total } \\
\hline & Média & $\mathrm{n}$ & SD & Média & $\mathrm{n}$ & SD & Média & $\mathrm{n}$ & $\mathrm{SD}$ \\
\hline $\begin{array}{l}\text { Ameaças de homicídio } \\
\text { por parte do suposto } \\
\text { abusador }\end{array}$ & 0.11 & 110 & 0.31 & 0.04 & 114 & 0.21 & 0.08 & 224 & 0.27 \\
\hline $\begin{array}{l}\text { Denúncias anteriores } \\
\text { (às autoridades) }\end{array}$ & 0.25 & 110 & 0.44 & 0.12 & 114 & 0.33 & 0.19 & 224 & 0.39 \\
\hline Denúncias retiradas & 0.09 & 110 & 0.29 & 0.02 & 114 & 0.13 & 0.05 & 224 & 0.23 \\
\hline $\begin{array}{l}\text { Detenções anteriores } \\
\text { do suposto abusador }\end{array}$ & 0.03 & 110 & 0.16 & 0.01 & 114 & 0.09 & 0.02 & 224 & 0.13 \\
\hline $\begin{array}{l}\text { Situações de violência } \\
\text { doméstica nas famílias } \\
\text { de origem dos supostos } \\
\text { vítima e agressor }\end{array}$ & 0.01 & 110 & 0.10 & 0.05 & 114 & 0.22 & 0.03 & 224 & 0.17 \\
\hline $\begin{array}{l}\text { Existência de outras } \\
\text { pessoas abusadas ou } \\
\text { assistindo aos abusos }\end{array}$ & 0.18 & 110 & 0.39 & 0.11 & 114 & 0.31 & 0.14 & 224 & 0.35 \\
\hline $\begin{array}{l}\text { Convicção de suposta } \\
\text { vítima de poder ser } \\
\text { alvo de tentativas de } \\
\text { homicídio }\end{array}$ & 0.03 & 110 & 0.16 & 0.02 & 114 & 0.13 & 0.02 & 224 & 0.15 \\
\hline $\begin{array}{l}\text { Existência de ideação } \\
\text { suicida por parte da } \\
\text { suposta vítima }\end{array}$ & 0.01 & 110 & 0.10 & 0.02 & 114 & 0.13 & 0.01 & 224 & 0.12 \\
\hline $\begin{array}{l}\text { Apoio social/familiar } \\
\text { com que conta a } \\
\text { suposta vítima. }\end{array}$ & 0.04 & 110 & 0.19 & 0.02 & 114 & 0.13 & 0.03 & 224 & 0.16 \\
\hline
\end{tabular}

\section{Queixas}

Foram consideradas queixas funcionais, situacionais e relativas à vivência do processo abusivo, incluindo nestas as de ordem afectiva e de relação.

Apenas em 16 relatórios (7.1\%) do total foram registadas as três ordens de queixas. Em $80 \%$ dos relatórios fazia-se referência a uma das queixas, enquanto em $12 \%$ eram omissas. Os relatórios onde foram referidas os três tipos de queixas, 7\% do total, distribuem-se de forma semelhante entre a Delegação e o GML. 
Tabela 6. Análise comparativa dos resultados obtidos nos itens relativos às Queixas por origem

\begin{tabular}{|c|c|c|c|c|c|c|c|c|c|}
\hline \multirow{2}{*}{ Referência } & \multicolumn{3}{|c|}{ Delegação } & \multicolumn{3}{|c|}{ Gabinete } & \multicolumn{3}{|c|}{ Total } \\
\hline & Média & $\mathrm{n}$ & $\mathrm{SD}$ & Média & $\mathrm{n}$ & SD & Média & $\mathrm{n}$ & SD \\
\hline Queixas funcionais & 0.81 & 110 & 0.39 & 0.94 & 114 & 0.24 & 0.88 & 224 & 0.33 \\
\hline Queixas situacionais & 0.57 & 110 & 0.50 & 0.34 & 114 & 0.48 & 0.46 & 224 & 0.50 \\
\hline $\begin{array}{l}\text { Queixas relativas à } \\
\text { vivência do abuso }\end{array}$ & 0.09 & 110 & 0.29 & 0.07 & 114 & 0.26 & 0.08 & 224 & 0.27 \\
\hline
\end{tabular}

\section{Lesões e/ou sequelas}

Praticamente $99 \%$ dos relatórios apresentaram-se adequados por incluírem toda a informação necessária, com uma pequena percentagem $(5.8 \%)$ de incorrecções na formatação.

\section{Exames complementares de diagnóstico}

Este capítulo não constava em 96 relatórios (43\%). Cerca de 40\% dos relatórios não continha qualquer descrição por não existirem exames complementares. Em 17\% dos relatórios, considerou-se o envio ao Serviço Social como exame complementar de diagnóstico, ou incluíram-se nesta rubrica dados documentais. Uma percentagem de 78\% dos relatórios do GML não tinha referência a este capítulo, o qual foi "apagado" do relatório. Em cerca de $40 \%$ do total dos relatórios não foi efectuada qualquer descrição por não existirem exames, mas esse facto foi indicado no relatório. Existem diferenças significativas entre os dois grupos como indica o $\chi^{2}\left(\chi^{2}=125.5 ; \mathrm{p}<0.001\right)$.

\section{Discussão}

Em 55\% dos casos a avaliação da Discussão estava correcta, enquanto em $27 \%$ não foi efectuada por não se ter concluído o relatório, já que se tratava de relatórios preliminares. Num conjunto que totaliza 18\% dos relatórios há imprecisões de análise, que se prendem com a inexistência de referência a discussão em relatórios onde era obrigatório que esta constasse.

Sob o ponto de vista da análise comparativa da presença nos relatórios dos dois itens relativos à discussão e que são o "nexo de causalidade" e a "data de cura ou consolidação", verificamos: quando há lugar a discussão, em 77\% dos relatórios provenientes da Delegação, faz-se menção aos dois itens considerados, enquanto nos provenientes do GML, o nexo de causalidade é referido em $53 \%$ dos relatórios e a data de cura ou consolidação em 38\%. No GML, em 42 relatórios (36.8\%) encontrou-se registo dos dois itens e em 18 relatórios (15.8\%) foi assinalado apenas o "nexo de causalidade" (tabela 7). 
Tabela 7. Análise comparativa dos resultados obtidos nos itens relativos à Discussão por origem

\begin{tabular}{|c|c|c|c|c|c|c|c|c|c|}
\hline \multirow{2}{*}{ Referência } & \multicolumn{3}{|c|}{ Delegação } & \multicolumn{3}{|c|}{ Gabinete } & \multicolumn{3}{|c|}{ Total } \\
\hline & Média & $\mathrm{n}$ & SD & Média & $\mathrm{n}$ & SD & Média & $\mathrm{n}$ & SD \\
\hline Nexo de causalidade. & 0.77 & 106 & 0.42 & 0.53 & 114 & 0.50 & 0.65 & 220 & 0.48 \\
\hline $\begin{array}{l}\text { Data da cura ou de } \\
\text { consolidação das lesões }\end{array}$ & 0.77 & 106 & 0.42 & 0.38 & 114 & 0.49 & 0.57 & 220 & 0.50 \\
\hline
\end{tabular}

\section{Conclusão preliminar}

Foram descritas conclusões preliminares em 51 relatórios, equivalente a $22 \%$ do total, o que corresponde exactamente à percentagem de relatórios preliminares.

Dos 51 relatórios terminados com este tipo de conclusão, 75\% pertenciam ao GML e 25\% à Delegação, estando de acordo com o número do relatório (preliminar) a que dizem respeito. Foram de $92.3 \%$ e $89.5 \%$ as percentagens de conclusões correctas, respectivamente da Delegação e do GML, em relação aos totais parciais. Não existem diferenças entre os relatórios proveniente de ambos os locais descritos $(\chi 2=0.351 ; \mathrm{p}<0.001)$.

\section{Conclusão final}

Dos 224 relatórios, 173 (77.2\%) apresentavam "conclusão final". Desses, 94\% estavam correctamente redigidas. O maior número de relatórios com conclusões finais pertenceu à Delegação, 97 contra 76 do GML, já que neste local tinha havido um maior número de conclusões preliminares, não existindo diferenças entre eles $(\chi 2=7.806 ; \mathrm{p}<0.001)$.

\section{Fotodocumentação}

Não existe qualquer fotodocumentação nos relatórios examinados, seja nos que foram realizados na Delegação ou no GML.

\section{Estudo comparativo das médias obtidas nas diferentes categorias de análise dos relatórios}

Comparámos as médias obtidas nos relatórios oriundos da Delegação do Norte e do GML de Viseu quanto às categorias constantes do guião. Constatámos que a categoria das "Lesões" é aquela cujos resultados se aproximam do máximo possível. Ao contrário, o "Contexto Familiar" e os "Antecedentes Pessoais" são as categorias que apresentam menos itens descritivos na glo- 
balidade dos relatórios. Exceptuando as categorias "Queixas" e "Conclusões Finais”, as pontuações atribuídas são favoráveis aos relatórios da Delegação. Existem diferenças, estatisticamente significativas, nas pontuações atribuídas nos "Dados Documentais", "Antecedentes Pessoais", "Contexto Familiar", "Discussão" e "Conclusão" entre os relatórios do GML e da Delegação (tabela 8).

Tabela 8. Análise comparativa das pontuações médias e desvio-padrão relativo às categorias constantes do guião de análise dos relatórios.

\begin{tabular}{|c|c|c|c|c|c|c|c|c|c|}
\hline \multirow{2}{*}{ Pontuações } & \multicolumn{3}{|c|}{ Delegação } & \multicolumn{3}{|c|}{ Gabinete } & \multicolumn{3}{|c|}{ Total } \\
\hline & Média & $\mathrm{n}$ & SD & Média & $\mathrm{n}$ & $\mathrm{SD}$ & Média & $\mathrm{n}$ & SD \\
\hline História do evento & 1.11 & 110 & 0.44 & 1.07 & 114 & 0.37 & 1.09 & 224 & 0.40 \\
\hline Dados documentais & 2.10 & 110 & 0.33 & 1.52 & 114 & 1.16 & 1.80 & 224 & 0.91 \\
\hline Antecedentes pessoais & 0.94 & 110 & 0.39 & 0.39 & 114 & 0.96 & 0.66 & 224 & 0.79 \\
\hline Contexto familiar & 0.22 & 110 & 1.02 & -0.89 & 114 & 0.45 & -0.35 & 224 & 0.96 \\
\hline Queixas & 0.80 & 110 & 1.01 & 1.00 & 114 & 0.70 & 0.90 & 224 & 0.87 \\
\hline Lesões & 2.91 & 110 & 0.35 & 2.90 & 114 & 0.44 & 2.91 & 224 & 0.40 \\
\hline $\begin{array}{l}\text { Exames complementa- } \\
\text { res de diagnóstico }\end{array}$ & 1.59 & 110 & 0.63 & 0.39 & 114 & 0.77 & 0.98 & 224 & 0.93 \\
\hline Discussão & 2.20 & 110 & 1.44 & 1.28 & 114 & 1.49 & 1.73 & 224 & 1.53 \\
\hline $\begin{array}{l}\text { Conclusões prelimi- } \\
\text { nares }\end{array}$ & 2.92 & 13 & 0.28 & 2.82 & 38 & 0.69 & 2.84 & 51 & 0.61 \\
\hline Conclusões finais & 2.72 & 97 & 0.85 & 2.91 & 76 & 0.49 & 2.80 & 173 & 0.72 \\
\hline
\end{tabular}

Um dado interessante a ter em conta é a análise da dispersão dos valores obtidos nos relatórios oriundos das duas origens geográficas: há maior dispersão de respostas nas categorias "Dados Documentais" e "Antecedentes pessoais" nos relatórios oriundos do GML; ao invés, há maior dispersão de respostas nos relatórios da Delegação nas categorias "Contexto Familiar" e "Queixas". Não há dispersão significativa na categoria "Lesões", seja na Delegação seja no GML, o que infere o raciocínio que todos dão idêntica e efectiva importância a esta categoria. Tais juízos podem ser vistos graficamente no quadro de boxplot seguinte (gráfico 1). 


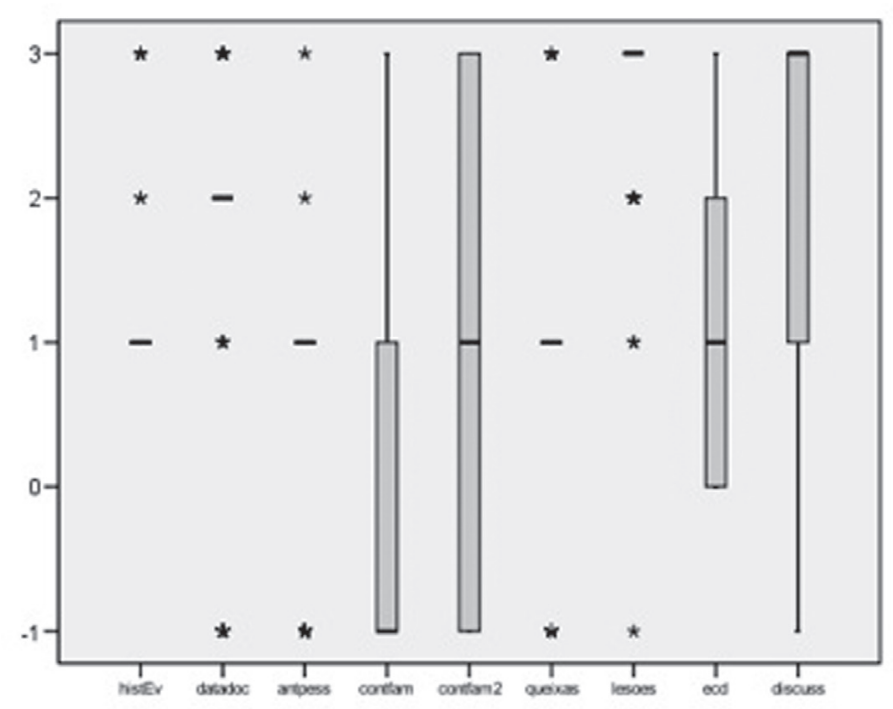

Gráfico 1. Box-plot comparativo da dispersão das pontuações atribuídas às categorias constantes do guião de análise dos relatórios

\section{Estudo correlacional e redução dos itens aos componentes principais}

Foi testada a hipótese teórica de que há diferenças nos registos dos aspectos que relevam do contexto situacional. Para testar à posteriori esta hipótese, que tinha inspirado teoricamente a grelha de análise, foram realizados estudos de correlação entre os itens da grelha relativos ao "Contexto familiar". O estudo correlacional permitiu validar genericamente a leitura que tinha sido feita inicialmente.

Efectuou-se uma análise estatística de redução da variância dos itens para identificação, a posteriori, dos principais componentes, para a qual se utilizou o método Varimax, disponibilizado pelo SPSS. A ferramenta estatística devolveu seis componentes principais responsáveis por 68.7\% da variância total dos dados (gráfico 2), que são:

a) $1^{\circ}$ componente: agrupa os itens 13.1 .1 (pessoas do agregado familiar), 13.1.4 (antecedentes patológicos do agregado familiar), 13.1.5 (comportamentos desviantes das pessoas no agregado familiar), 13.2 (data de início da relação actual), 13.3 (data de início do abuso), 13.4 (tipo de abuso inicial) e 13.15 (outras pessoas abusadas ou assistindo aos abusos), que genericamente poderíamos associar à categoria de caracterização das pessoas do agregado familiar e caracterização da VRI, que explica $34.3 \%$ da variância; 
b) $2^{\circ}$ componente: inclui os itens 13.8 (existência de agressões durante a gravidez), 13.9 (existência de ameaças com arma branca ou de fogo), 13.18 (existência de apoio familiar ou social) que, em conjunto, representam $10.1 \%$ da variância e que se referem à ideia de necessidade de protecção;

c) $3^{\circ}$ componente: junta os itens 13.5 (formas de evolução dos abusos), 13.6 (forma de evolução dos abusos quanto à frequência), 13.7 (forma de evolução dos abusos quanto ao tipo e grau de ameaças), 13.10 (ameaças de homicídio por parte do abusador), 13.16 (convicção da vítima de poder ser vítima de homicídio) representando 6.98\% da variância e que nos mostram uma ideia de indícios de existência de perigo;

d) $4^{\circ}$ componente: agrupa os itens 13.1.2 (escolaridade do agregado familiar) e 13.1.3 (profissões das pessoas do agregado familiar), com $6.62 \%$ da variância, que poderemos associar a uma caracterização sócio-académica;

e) $5^{\circ}$ componente: associa os itens 13.13 (detenções anteriores do abusador, 13.14 (violência nas famílias de origem do abusador ou da vítima), e 13.17 (ideação suicida por parte da vítima), com 5.5\% da variância, que se refere às condições psico-familiares da relação de intimidade;

f) $6^{\circ}$ componente: composto pelos itens 13.11 (queixas anteriores às autoridades) e 13.12 (queixas retiradas), referentes a 5.1\% da variância, e que, transmitem a ideia de manutenção e continuidade do processo de abuso.

O resultado de tal estudo pode apreciar-se de forma gráfica (gráfico 2):

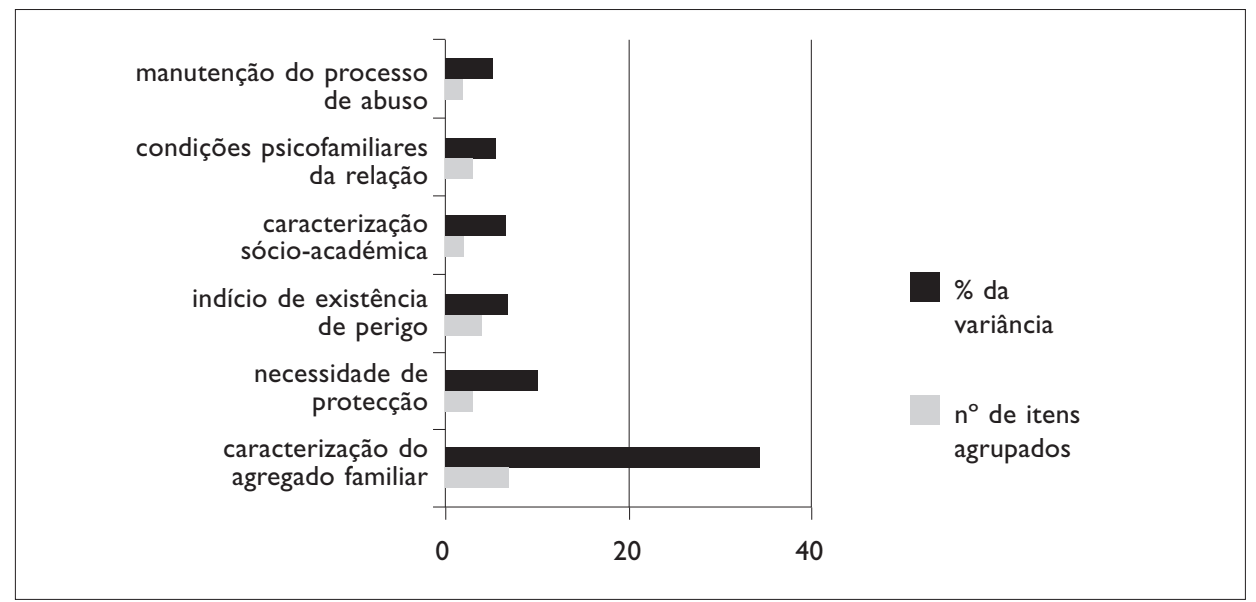

Gráfico 2. Capacidade explicativa da variância dos componentes em que foram agrupados os itens do Contexto Familiar. 


\section{Discussão}

Elaboraremos este capítulo referindo-nos, tal como no capítulo dos Resultados, aos diversos passos do relatório pericial.

\section{História do evento}

Os peritos médicos, na sua globalidade, parecem não considerar a descrição da "História do Evento" muito importante, uma vez que ela só aparece completa em cerca de 5\% dos relatórios, sendo essa percentagem idêntica em ambos os departamentos considerados (Delegação do Norte e GML de Viseu). $\mathrm{Na}$ verdade, $95 \%$ dos relatórios apresenta uma descrição que indica data e hora, tipo de ocorrência, agressor e instrumento de agressão, mas não faz, por sistema, referência à descrição da ocorrência. Este último aspecto é no entanto particularmente importante para a compreensão não só do tipo de abuso em causa, como da sua gravidade, bem como para o estabelecimento do nexo de causalidade entre o traumatismo e o dano. Note-se que um dos motivos frequentemente referidos pelos peritos para não desenvolverem determinados aspectos num relatório tem a ver com o facto da aplicação informática em uso no INML não contemplar, de forma explícita, esse mesmo aspecto; importa contudo ter em conta que nenhum instrumento deste tipo poderá contemplar todas as especificidades de cada caso e, muito menos, se poderá substituir ao perito; o perito terá sempre espaço e liberdade para descrever no relatório o que considerar relevante face a cada situação em concreto.

\section{Dados documentais}

$\mathrm{Na}$ apreciação dos relatórios dos peritos, constata-se que, de uma forma geral, quando existem dados documentais, eles são sempre referidos. Contudo, os peritos do GML têm por hábito "apagar" esta rubrica do relatório quando não existem dados documentais para transcrever. Esta atitude, uma vez que deixa dúvidas sobre a possível existência daqueles dados, penalizou a avaliação dos relatórios.

\section{Antecedentes pessoais}

A esmagadora maioria dos relatórios faz menção, apenas, aos antecedentes patológicos e traumáticos, nada dizendo sobre os hábitos de consumo (dos 224 relatório, apenas 2 incluíam essa referência). O facto de "hábitos de consumo" não estar mencionado na aplicação informática, pode influenciar este resultado, 
mas aplica-se também aqui o que acima se referiu quanto ao espaço de liberdade do perito para descrever tudo o que de relevante considere para o relatório, independentemente do modelo informático existente, o qual não é limitativo.

\section{Contexto familiar}

Apesar do programa informático conter alguns dos itens considerados no "Contexto Familiar" da nossa ficha de avaliação, os peritos, habitualmente, não lhes fazem referência, ou limitam-se a dizer que "há história de maus tratos". Note-se que, além de se caracterizarem aqui os membros do agregado familiar, é neste capítulo que se descreve toda a história do abuso, dado que este constitui uma história que vem de trás e que importa perceber desde o seu início (modo como se desencadeou, forma como evoluiu, frequência, duração, gravidade, tipo de práticas implicadas, pessoas envolvidas, suas idades, profissões e habilitações académicas, histórias de abuso em relações pretéritas, bem como nas famílias de origem de vítima e abusador, existência de ameaças com armas, existência de denúncias apresentadas a autoridades, existência de ideação suicida ou homicida, existência de detenções anteriores do abusador, etc.) (Magalhães et al, 2010 a.). Em mais nenhuma parte do relatório o historial do abuso será descrito, já que a "História do Evento", da forma que está actualmente organizado o modelo de relatório pericial, é apenas relativa ao episódio agudo (evento) que traz a vítima ao exame médico-legal e que, se não for contextualizado num quadro de reiteração das agressões e de comportamentos que configurem este tipo de práticas abusivas, pode ser entendido apenas como uma simples ofensa à integridade física (ainda que o actual Código Penal não exija que exista reiteração para poder considerar o crime de Violência Doméstica ou de Maus Tratos - $\operatorname{art}^{\circ} \mathrm{s} 152^{\circ}$ e $\left.152^{\circ} \mathrm{A}\right)$. Por outro lado, a descrição de todos estes aspectos permitirá fazer também uma avaliação do risco, fundamental para a definição das adequadas medidas de protecção da vítima.

Na Delegação, existindo uma técnica de Serviço Social, uma boa parte dos peritos remete para essa profissional a avaliação deste item. Nos casos em que existe um relatório Social, consideramos que seria de toda a utilidade que os peritos o utilizassem posteriormente na "Discussão" e nas “Conclusões", nomeadamente na avaliação de risco.

Em relação ao GML, onde não existe técnico de Serviço Social, cabe ao perito proceder à recolha de todos os elementos que se lhe afigurem importantes para a descrição do contexto familiar, o que geralmente não acontece (94.7\%), pelo que, nesta matéria, se nos afigura verdadeiramente fundamental investir em termos de sensibilização e formação dos peritos nesta área. Note-se, contudo, que será também fundamental que este tipo de exame seja considerado diferente das avaliações do dano corporal em caso de ofensa à 
integridade física em geral, porque o tipo de prática que aqui se preconiza e a própria abordagem da vítima o tornam necessariamente mais moroso.

\section{Queixas}

A maioria dos relatórios refere as queixas de ordem física e as suas repercussões a nível funcional ou situacional, quando elas existem, mas não refere nada quando estas não existem. Por outro lado, há uma clara ausência das queixas relacionadas com a vivência do processo abusivo - apenas $8 \%$ dos relatórios apresenta alguma informação sobre este aspecto. Tal como no item anterior, os peritos não valorizam devidamente a vivência do processo de vitimação, aparentemente nem sequer o questionam, embora as consequências psico-sociais constituam um dos aspectos principais da VRI. Os valores obtidos são idênticos na Delegação e no GML, o que significa que, de um modo geral, os peritos não estão alertados para a problemática da VRI e se limitam a valorizar o dano físico. Parece assim constatar-se um silenciamento da dimensão psicológica do abuso, que tal como refere a literatura, tem muito mais importância para a avaliação deste tipo de violência e provoca muito mais sequelas do que a dimensão física (Gelles, 1997; Acosta, 2001; Asensio, 2008).

\section{Lesões e sequelas}

Como se esperava, essa descrição está correcta em quase todos os relatórios. Todos os peritos são "peritos" em dano físico, não havendo diferenças significativas entre a avaliação efectuada na Delegação e no GML.

\section{Exames complementares de diagnóstico}

No que respeita aos relatórios periciais analisados é de notar que em 43\% dos casos este capítulo não consta. De facto, no GML, a grande maioria das vezes não existem estes exames complementares pelo que os peritos "apagam" o capítulo. Importará contudo ponderar até que ponto, e à semelhança do que se preconiza nas normas periciais relativamente aos abusos em crianças, se não seria de requerer sistematicamente um exame psicológico a todas as vítimas de VRI (Magalhães et al, 2010 b.).

\section{Discussão}

Cerca de metade dos relatórios analisados estavam correctamente discutidos e em cerca de um quarto não tinha sido efectuada discussão por o documento 
não estar ainda concluído - relatórios preliminares ou intercalares. Numa parte considerável (18\%) houve imprecisão de análise, o que se prendeu com a inexistência de referências a discussão em relatórios onde era obrigatório que esta constasse. Este facto ocorreu tanto em relatórios provenientes da Delegação (14\%), como do GML (22\%), em que, apesar de existir um relatório final, não se fez Discussão. O que se passa, por vezes, é que os peritos entendem que se a conclusão é "nada se pode concluir", então não há nada a discutir e muitas vezes chegam a "apagar" esse capítulo.

Importa contudo assinalar que se em alguns relatórios elaborados em sede de Direito Penal, relativos a ofensas à integridade física, este capítulo pode não se mostrar relevante dada a singeleza do quadro médico-legal em causa (Magalhães et al, 2010 c.), nos casos de VRI importará sempre discutir a questão do nexo de causalidade, das sequelas, que se não existirem do ponto de vista físico, existirão pelo menos do ponto de vista psico-social, bem como do risco para a vítima e para eventuais crianças ou pessoas idosas que possam estar expostas a esse tipo de violência (Dutton \& Kropp, 2000; Gondolf, 2000; Campbell et al., 2003; Magalhães, 2010).

\section{Conclusões}

No que respeita à apreciação dos relatórios e tendo sido esta rubrica dividida em dois sub-capítulos, "conclusões preliminares" e "conclusões finais", refira-se que $23 \%$ dos relatórios apresentaram conclusões preliminares, o que corresponde à percentagem de relatórios preliminares analisados, indicando isto que foi necessário esperar pelo envio de informação adicional, a maioria das vezes informação clínica relativa à assistência médica na altura da ocorrência, ou que foi necessário esperar pela cura das lesões para se poder retirar conclusões. O maior número de relatórios preliminares pertenceu ao GML devido ao facto de os peritos solicitarem, com maior frequência, os relatórios dos serviços de saúde a que as vítimas recorreram. O objectivo será confirmar a história do evento ou as lesões que dele decorreram e que, eventualmente, na altura do exame já não serão tão perceptíveis. Tal diferença, quantitativamente comprovada, permite-nos referir o peso das culturas profissionais como a explicação mais plausível, devendo contudo assinalarse que se poderão dispensar tais registos e concluir-se o relatório caso as lesões sejam observáveis (geralmente o tempo que medeia entre a agressão e o exame não ultrapassa as 72 horas) e não tenham sido realizados exames de diagnóstico complementar no hospital (imagiológicos, por exemplo), que importe analisar. 


\section{Fotodocumentação}

Não foi realizado registo fotográfico em nenhum dos 224 relatórios analisados, fossem da Delegação ou do GML. No entanto, estando teoricamente sustentada a importância da imagem como elemento de diagnóstico e de evidência, recomenda-se a sua utilização sistemática (Magalhães et al, 2010 a.) e indexada no programa informático em que se regista o exame. Uma vez mais a falta deste procedimento pode estar relacionada com a rapidez exigida ao perito na realização da perícia dado esta ser agendada nos moldes e para o tempo de uma perícia de ofensa à integridade física em geral.

\section{Conclusão}

A análise dos relatórios periciais de Clínica Forense em casos de VRI permitiu concluir genericamente:

1) Tanto na Delegação como no GML os relatórios estão correctos, na sua grande maioria, no que se refere à descrição e valoração das lesões;

2) Existem contudo lacunas relacionadas especificamente com os casos de VRI, que de forma geral são tratados como situações de ofensas à integridade física, não sendo significativamente diferentes entre as duas instituições:

a) Não são levados em conta, alguns dos elementos essenciais para a caracterização do abuso e, a partir daí, avaliação do risco e descrição pormenorizada da situação de VRI que seja mais consentânea com os requisitos exigidos pela definição de VRI do Conselho da Europa e pela necessidade de celeridade que a Lei impõe;

b) Ignora-se a forma como a vítima vive o processo abusivo, o que impede a ponderação da necessidade de atribuir, eventualmente, estatuto de vítima ou de vítima especialmente vulnerável;

c) Os relatórios mostraram-se redutores quando na "discussão" (quando existe), apenas se referem ao "nexo de causalidade" e à "data da cura/ consolidação", elementos que servindo como ponto fulcral da prova pericial, são, no entanto, insuficientes quando a Lei obriga a que se garantam os direitos das vítimas e se assegure a sua protecção.

d) Não é feita fotodocumentação.

3) Estes exames são mais complexos e mais morosos do que os relativos às agressões em geral, pelo que lhes deverá ser atribuído um maior tempo para a sua realização a par, necessariamente, da revisão do valor das custas do tipo de perícia em causa;

4) Importará investir seriamente na sensibilização e formação dos peritos para a realização deste tipo de perícias. 
O trabalho empírico realizado permitiu concluir que se torna necessário continuar a promover uma melhor qualidade na avaliação das vítimas de VRI no que concerne aos exames de Clínica Forense. A avaliação do risco e a utilização de instrumentos de avaliação de risco que têm sido desenvolvidos numa tentativa de prevenir novos abusos, para além do nível oferecido pelos factores de risco, parece ser a forma mais adequada de atingir esse objectivo.

No que diz respeito aos relatórios de Clínica Forense, o achado que importa ressaltar é o de que os peritos médicos (apesar de oriundos de dois sistemas institucionais diferentes) continuam a tratar os casos de VRI como casos "vulgares" de Direito Penal, dando especial atenção ao dano corporal, mas ignorando os problemas psicológicos e sociofamiliares.

A VRI é um crime público. Inclui todas as formas de abuso, físico, sexual, emocional, social, afecta a dinâmica do relacionamento do casal, a família, o trabalho, a sociedade em geral e, em última instância, constituiu uma ameaça para a democracia. As vítimas têm o direito de ser avaliadas, tratadas, mas, acima de tudo, protegidas de futura violência, porque é a sua segurança e não a penalização do agressor, a preocupação principal da intervenção em violência doméstica. Em todo este processo, a intervenção pericial constitui um momento fundamental de apoio à vítima e á boa administração da Justiça.

\section{Referências}

Acosta, M. Valoración médico-forense del origen y resultado de la violencia psíquica contra las mujeres. Barcelona: Crítica; 2001.

Alberdi, I. \& Matas, N. La Violencia domestica. Informe sobre los maltratos en Espana. Barcelona: Fundación La Caixa; 2002.

Campbell, JC. Nursing assessment for risk of homicide with battered women. Advance in nursing 1986; 8, (4): 36-51.

Campbell, JC. et al. Risk factors for femicide in abusive relationships: results from a multisite case control study. American Journal of Public Health 2003; 93, (7):1089-1097.

Corsi, J. Maltrato y abuso en el âmbito Doméstico. Buenos Aires: Paidós; 2003.

Dutton, DG. \& Kropp, PR. A review of domestic violence instruments. Trauma Violence and Abuse 2000; 1: 171-181.

Gelles, RJ. Intimate violence in families. Thousand Oaks: Sage; 1997.

Gondolf, EW. Batterer intervention systems: issues, outcomes and recommendations. Thousand Oaks: Sage; 2000.

Kropp, PR., Hart, SD., Webster, CD. \& Eaves, D. Manual of spousal assault risk assessment guide. Vancouver: British Columbia Institute on Family Violence; 1994.

Kropp, PR., Hart, SD., Webster, CD. \& Eaves, D. The spousal assault risk assessment guide (SARA): reliability and validity in adult male offenders. Law and Human Behaviour 2000; 24 (1): 101-118. 
Lisboa, M., Carmo, I., Vicente, L. \& Nóvoa, A. Os custos sociais e económicos da violência contra as mulheres. Lisboa: CIDM; 2003.

Machado, C., Matos, M. \& Gonçalves, M. Inventário sobre violência conjugal (IVC). Braga: Universidade do Minho; 2000. (doc. policopiado).

Magalhães, T. Violência e Abuso. Respostas Simples para Questões Complexas. Coimbra: Imprensa da Universidade de Coimbra; 2010.

Magalhães, T, Corte-Real, F, Costa Santos, J \& Vieira, DN. Recomendações gerais para a realização de relatórios periciais de Clínica Forense relativos ao dano pós-traumático. Revista Portuguesa do Dano Corporal 2010; 20: 53-61. (a)

Magalhães, T, Ribeiro, CS, Jardim, P \& Vieira, DN. Procedimentos no âmbito da recolha de informação, exame físico e colheita de vestígios em crianças e jovens vítimas de abuso físico e/ou sexual. Acta Médica Portuguesa 2010; 23(6) (b)

Magalhães, T, Corte-Real, F, Costa Santos, J \& Vieira, DN. Recomendações Gerais para a Realização de Relatórios Periciais de Clínica Forense no Âmbito do Direito Penal. Revista Portuguesa do Dano Corporal 2010; 20: 63-68. (c)

Metropolitan Police Service. MPS Risk assessment model for domestic violence case. London: MPS; 2003.

Tuckman, B.W. Manual de investigação em Educação. Lisboa: Gulbenkian; 2003.

Vieira, DN. Assessment of bodily damage in civil law: harmonization of an expert protocol. Revista Portuguesa do Dano Corporal. XII, (13); 2003.

Villora, JMG., Ribes, AI., Garcia, HM. Protocolos sobre violência de género. Valência: Tirant lo Blanch; 2009.

Resumo: A perícia médico-legal em casos de violência nas relações de intimidade - Contributo para a qualidade

A violência nas relações de intimidade (VRI) é uma das formas mais preocupantes de violência doméstica e parece estar a aumentar em número de casos relatados e grau de violência. A avaliação destas vítimas é uma das principais funções da Clínica Forense.

Neste trabalho pretendeu-se fazer uma avaliação da qualidade dos relatórios periciais procurando saber se o exame da vítima, realizado no âmbito do Direito Penal, permite uma correcta avaliação, tanto das ofensas corporais, como da "circunstância" da vítima, de forma a produzir um instrumento de prova legalmente útil. Procurou-se verificar se os itens escolhidos para realizar aquela avaliação estão adequados e são suficientes, nomeadamente no que concerne à protecção eficaz e célere das vítimas.

Foram analisados 224 relatórios de Clínica Forense produzidos na Delegação do Norte do Instituto Nacional de Medicina Legal e no Gabinete Médico-Legal de Viseu.

A análise permitiu concluir que os peritos médicos, na generalidade, não valorizam aspectos considerados essenciais na avaliação das vítimas, nomeadamente a história da ocorrência, os antecedentes pessoais e o contexto familiar, bem como as queixas de ordem psicológica e a vivência do processo abusivo.

Palavras-chave: Violência na relação de intimidade; perícia médico-legal; vítima. 
Summary: A forensic expertise in intimate partner violence - Contribute to quality Intimate partner violence (IPV) is one of the most worrisome forms of domestic violence and seems to increase in number of reported cases and degree of violence. Assessment of these victims is a major function of the Forensic Clinic.

This work was intended to make an assessment of the quality of expert reports and to know whether the victim examination, held under the Criminal Law, allows a correct assessment, both the injury, and the victim's context, to enable the production of an effective proof instrument. We also sought to ascertain whether the items selected to conduct the evaluation of the victim are adequate and sufficient to enable a more effective approach that kind of violence, especially as regards the effective protection of victims.

The analysis focused on 224 reports of Clinical Forensic produced in the North's Delegation of the National Institute of Forensic Medicine and Medical-Legal Office of Viseu.

The analysis concluded that, globally, medical experts, do not value some of the points deemed essential in the evaluation of victims, including the history of the event, the personal background and family history as well as psychological complaints and experience of the abusive process.

Key-words: Intimate partner violence; forensic expertise; victim.

Résumé: Une expertise médico-légale de la violence dans les relations d’intimité - Contribution à la qualité

La violence dans les relations d'intimité est une des formes le plus préoccupante de violence domestique et semble être en augmentation en nombre et en degré de cas signalés de violence. L'évaluation de ces victimes est une des principales fonctions de la Clinique Médico-légale. Ce travail avait pour but de procéder à une évaluation de la qualité des rapports d'experts, en cherchant de savoir si l'interrogatoire de la victime, qui s'est tenue en vertu de la loi pénale, permet une évaluation correcte de la lésion à la fois que les «circonstances» de la victime, de manière à produire un instrument de preuve légalement utile. Nous avons cherché à vérifier que les options choisies pour réaliser cette évaluation sont appropriées et suffisantes, en particulier en ce qui concerne la protection effective et rapide des victimes. Nous avons analysé 224 rapports de clinique médico-légale produits dans la Délégation du Nord de l'Institut National de Médecine Légale et dans le Cabinet Médico-légale de Viseu. L'analyse a conclu que les experts médicaux en général ne valorisent pas les aspects considérés comme essentiels dans l'évaluation des victimes, notamment l'histoire du présent évènement, les antécédents personnels et l'histoire familiale ainsi que les plaintes d'ordre psychologique et l'expérience du processus abusif.

Mots-clés: Violence dans les relations d'intimité; expertise médico-légale; victime.

\title{
Pedido de separatas:
}

\author{
M. JOSÉ MOURAZ \\ mariajosemouraz@hotmail.com
}




\section{Anexo}

Ficha de supervisão dos relatórios de clínica médico-legal relativos a situações de violência nas relações de intimidade (VRI)

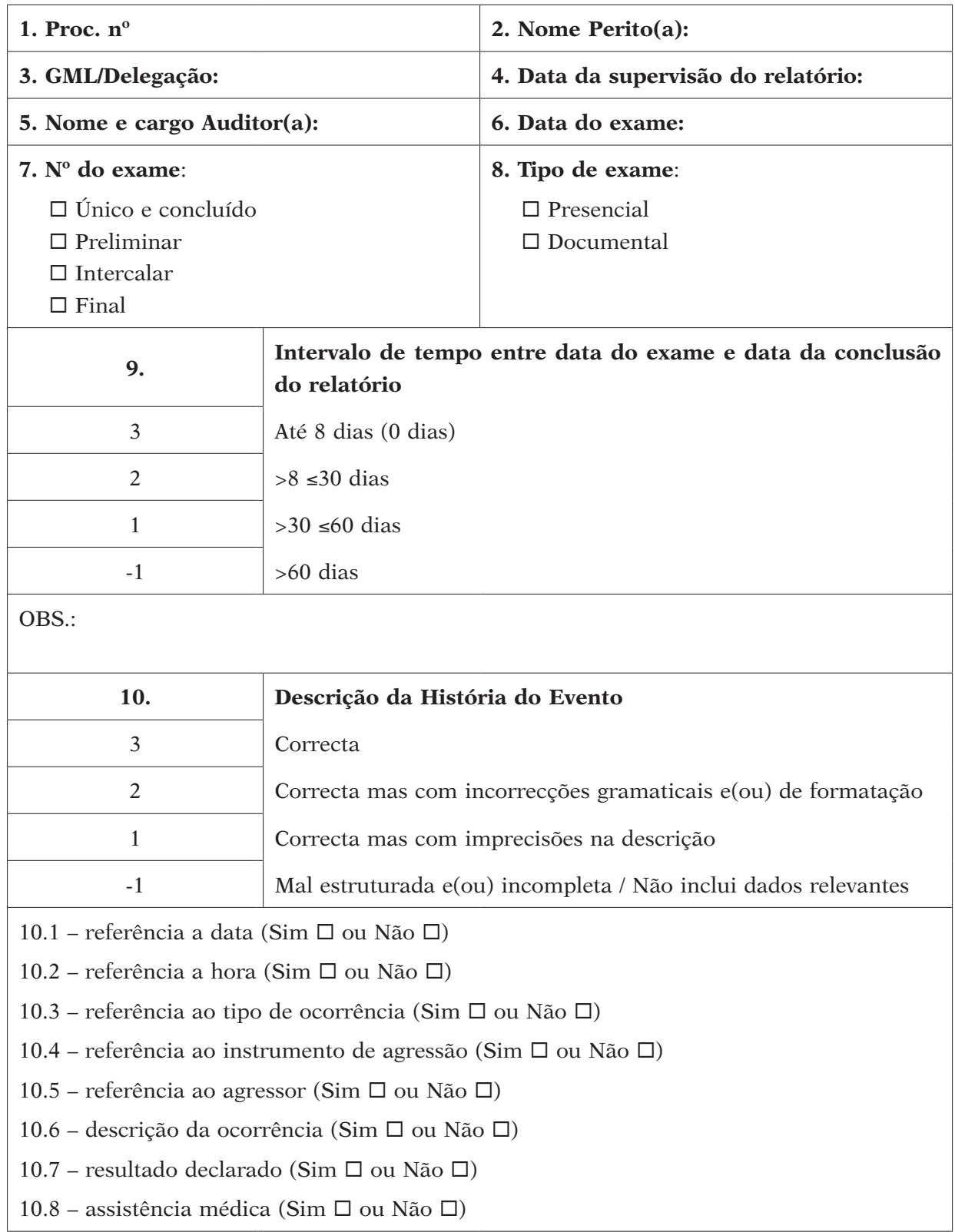


13.5 - Referência à forma de evolução dos abusos quanto ao seu tipo

(Registado $\square$ ou Não registado $\square$ )

13.6 - Referência à forma de evolução dos abusos quanto à sua frequência

(Registado $\square$ ou Não registado $\square$ )

13.7 - Referência à forma de evolução dos abusos quanto ao tipo e grau de ameaças (Registado $\square$ ou Não registado $\square$ )

13.8 - Referência à existência de agressões durante a gravidez (Registado $\square$ ou Não registado $\square$ )

13.9 - Referência a ameaças com armas (Registado $\square$ ou Não registado $\square$ )

13.10 - Referência à existência de ameaças de homicídio por parte do suposto abusador (Registado $\square$ ou Não registado $\square$ )

13.11 - Referência a queixas anteriores (às autoridades) (Registado $\square$ ou Não registado $\square$ )

13.12 - Referência a queixas retiradas (Registado $\square$ ou Não registado $\square$ )

13.13 - Referência a detenções anteriores do suposto abusador (Registado $\square$ ou Não registado $\square$ )

13.14 - Referência a situações de violência doméstica nas famílias de origem dos supostos vítima e agressor (Registado $\square$ ou Não registado $\square$ )

13.15 - Referência à existência de outras pessoas abusadas ou assistindo aos abusos (Registado $\square$ ou Não registado $\square$ )

13.16 - Referência à convicção de suposta vítima de poder ser alvo de tentativa de homicídio (Registado $\square$ ou Não registado $\square$ )

13.17 - Referência à existência de ideação suicida por parte da suposta vítima (Registado $\square$ ou Não registado $\square$ )

13.18 - Referência ao apoio social/familiar com que conta a suposta vítima (Registado $\square$ ou Não registado $\square$ )

\begin{tabular}{|c|l|}
\hline $\mathbf{1 4 .}$ & Descrição das Queixas \\
\hline 3 & Correcta \\
\hline 2 & Correcta mas com incorrecções gramaticais e(ou) de formatação \\
\cline { 1 - 2 } & Correcta mas com imprecisões na descrição \\
\hline 1 & Mal estruturada e(ou) incompleta / Não inclui dados relevantes \\
\hline
\end{tabular}

14. Referência a queixas

14.1 -De ordem funcional (Registado $\square$ ou Não registado $\square$ )

14.2 -De ordem situacional (Registado $\square$ ou Não registado $\square$ )

14.3 -Relativas à vivência do processo abusivo (Registado $\square$ ou Não registado $\square$ ) 


\begin{tabular}{|c|c|}
\hline 15. & \multirow{5}{*}{$\begin{array}{l}\text { Descrição das Lesões e/ou Sequelas } \\
\text { Correcta } \\
\text { Correcta mas com incorrecções gramaticais e(ou) de formatação } \\
\text { Correcta mas com imprecisões na descrição } \\
\text { Mal estruturada e(ou) incompleta / Não inclui dados relevantes }\end{array}$} \\
\hline 3 & \\
\hline 2 & \\
\hline 1 & \\
\hline-1 & \\
\hline \multicolumn{2}{|l|}{ OBS: } \\
\hline 16. & Descrição dos Exames Complementares de Diagnóstico \\
\hline 3 & Correcta \\
\hline 2 & Correcta mas com incorrecções gramaticais e(ou) de formatação \\
\hline 2 & $\begin{array}{l}\text { Não efectuada qualquer descrição por não existirem exames com- } \\
\text { plementares }\end{array}$ \\
\hline 1 & $\begin{array}{l}\text { Correcta mas com imprecisões na descrição / Inclui exames a constar } \\
\text { dos Dados Documentais }\end{array}$ \\
\hline-1 & Mal estruturada e(ou) incompleta / Não inclui dados relevantes \\
\hline \multicolumn{2}{|l|}{ OBS.: } \\
\hline 17. & Discussão \\
\hline 3 & Correcta \\
\hline 2 & Correcta mas com incorrecções gramaticais e(ou) de formatação \\
\hline 1 & Não efectuada por não se ter concluído o relatório \\
\hline-1 & Com imprecisões de análise / \\
\hline \multicolumn{2}{|c|}{$\begin{array}{r}17.1 \text { - Referência ao nexo de causalidade } \\
\text { (Registado } \square \text { ou Não registado } \square \text { ) }\end{array}$} \\
\hline \multicolumn{2}{|c|}{$\begin{array}{l}17.2 \text { - Referência à data da cura ou de consolidação das lesões } \\
\text { (Registado } \square \text { ou Não registado } \square \text { ) }\end{array}$} \\
\hline 18.A & Conclusão preliminar \\
\hline 3 & Correcta \\
\hline 2 & Correcta mas com incorrecções gramaticais e(ou) de formatação \\
\hline 1 & Desnecessária nova presença da vítima \\
\hline-1 & $\begin{array}{l}\text { Solicitação de elementos clínicos* incorrecta / Desnecessária a } \\
\text { solicitação feita** }\end{array}$ \\
\hline \multicolumn{2}{|l|}{ OBS.: } \\
\hline
\end{tabular}


35 A perícia médico-legal em casos de violência nas relações de intimidade. Contributo para a qualidade

\begin{tabular}{|c|c|}
\hline 18.B & \multirow{5}{*}{$\begin{array}{l}\text { Conclusão final } \\
\text { Correcta } \\
\text { Correcta mas com incorrecções gramaticais e(ou) de formatação } \\
\text { Revela discrepâncias entre o mecanismo do traumatismo, as queixas } \\
\text { e o exame físico } \\
\text { Incorrecta / Contradições ou lacunas relevantes / Sem elementos } \\
\text { suficientes para concluir }\end{array}$} \\
\hline 3 & \\
\hline 2 & \\
\hline 1 & \\
\hline-1 & \\
\hline \multicolumn{2}{|l|}{ OBS.: } \\
\hline 19. & \multirow{3}{*}{$\begin{array}{l}\text { Fotodocumentação (não contabilizada na pontuação final) } \\
\text { Realizada } \\
\text { Não realizada }\end{array}$} \\
\hline 1 & \\
\hline 0 & \\
\hline \multicolumn{2}{|l|}{ OBS.: } \\
\hline 20. & \multirow{3}{*}{$\begin{array}{l}\text { Apreciação final - Somatório dos itens anteriores } \\
\text { Relatório correctamente elaborado } \\
\text { Relatório adequadamente elaborado com ligeiras deficiências, } \\
\text { a corrigir }\end{array}$} \\
\hline Muito Bom : 26 a 30 & \\
\hline Relevante : 19 a 25 & \\
\hline Adequado: 11 a 18 & $\begin{array}{l}\text { Relatório com deficiências importantes, merecendo ser revisto } \\
\text { e discutido com o (a) perito (a) }\end{array}$ \\
\hline Desadequado: -10 a 10 & $\begin{array}{l}\text { Relatório incorrectamente elaborado, exigindo, eventualmente, melhor } \\
\text { formação do (a) perito(a) }\end{array}$ \\
\hline OBS.: & \\
\hline
\end{tabular}

